\title{
Study on the particle size reduction by milling of quartz sand for magnetic separation
}

\author{
Florin POPA ${ }^{1, a^{*}}$, Loredana COPIL ${ }^{1, b}$, Victor CEBOTARI ${ }^{1, \mathrm{c}}$, Traian Florin \\ MARINCA ${ }^{1, d}$, Bogdan Viorel NEAMȚU ${ }^{1, e}$, Niculina Argentina SECHEL ${ }^{1, f}$, and lonel \\ CHICINAȘ ${ }^{1,9}$ \\ ${ }^{1}$ Technical University of Cluj-Napoca, 103-105 Muncii Avenue, 400641, Romania \\ aflorin.popa@stm.utcluj.ro, 'bloredana_copil@yahoo.com, 'Victor.Cebotari@stm.utcluj.ro,

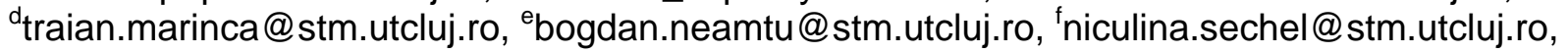 \\ glonel.Chicinas@stm.utcluj.ro \\ * corresponding author
}

Keywords: Quartz sand, Milling, Electron microscopy, Particle size.

\begin{abstract}
For being used in crystal glass industry, the iron content of quartz sand must be under $0.09 \%$. If the reserve contains a higher quantity, methods for iron reduction must be used. Usually the iron phases are present in large quantity in the small particle size fraction. For reducing the sand grain size, milling was performed on a planetary ball mill. Different ball/powders ratio were studied for determining an optimum particle size vs. milling duration. The particle size was determined for each milling experiment. Using Energy Dispersive X-ray spectroscopy (EDX), the elemental distribution for the particle was quantified. By X-ray diffraction, the phase distribution of the sand was analyzed and correlated with the chemical composition. The phases are changing their ratio versus the grain size. The main phase is $\mathrm{SiO}_{2}$ as quartz, accompanied by minor phases: iron oxides $\left(\mathrm{Fe}_{3} \mathrm{O}_{4}, \mathrm{Fe}_{2} \mathrm{O}_{3}\right.$, and $\left.\mathrm{FeTiO}_{3}\right)$ and some oxide of $\mathrm{Al}, \mathrm{Na}, \mathrm{Ca}$, and $\mathrm{K}$. Testes for magnetic separation were performed for validating the method.
\end{abstract}

\section{Introduction}

The quartz sand is the raw material for glass industry. Unfortunately, as all raw materials, quartz sand purity is the limiting criterion for his usage, since the structure and composition give the properties, the usage and classification criteria for glasses [1]. The most detrimental impurity in the quartz sand is iron, followed by some other metallic oxides (titanium, cobalt, copper, etc.). The effect of metallic impurities in the sand is most commonly observed in color of the resulting glass [2]. The minimum iron quantity in the sand for obtaining a color glass is $0.1 \%$. The classical way for iron removing is flotation, using toxic reagents as amine, $\mathrm{NaOH}$ or $\mathrm{H} 3 \mathrm{PO} 4$ [3 5]. A cleaner approach is magnetic separation [6]. In magnetic separation experiments, the content in magnetic phase (iron oxides) and particle size represent a key factor for an efficient removing setup [6]. Also, the different types of magnetic separators are considered [7].

A method of controlling the particle size of the sand is by ball milling [8]. In the milling experiments the particle size modification is realized by collision events between balls and sand particles [8]. For our studies is suitable that a high productivity to be achieved, at small milling time and the powder to be produced in a continuous way [9]. For high productivity, the quantity of sand is analyzed and in the milling experiments can be expressed in the form of ball to powder mass ratio (BPR). A high BPR means less quantity of material for processing and small BPR means high material quantity introduced in milling chamber. One purpose of this study is to determine optimal condition of sand milling considering different BPR and milling times. 
The ball milling was found to be useful in sand purification and particle size reduction [10].

In the milled sand it is important to have an insight on the iron phase distribution in the particles [11]. Scanning electron microscopy (SEM) coupled with X-ray energy dispersive spectrometry (EDX) was found to be a suitable technique for sand characterization, as proved by several studies [12 - 16].

In the present study, the particle size, the iron distribution and iron quantity is studied for the quartz sand ball milled, in order to establish the optimum parameters for magnetic removal.

\section{Experimental}

The particle size analysis was performed on standard sieving method using sieves in the range 40 $-800 \mu \mathrm{m}$. The standard sieved sand quantity was $100 \mathrm{~g}$. Multiple sieving were performed to obtain statistical data. Supplementary, particle size distribution analysis were recorded using an Analysette 22 Nano Tec particle analyzer. The size range was from $0.1 \mu \mathrm{m}$ to $135 \mu \mathrm{m}$. From the particle size distribution, the parameters D10, D50 and D90 were determinate. D10, D 50 and D90 represents the mean powder diameter equal with a diameter more or equal with 10, 50 and $90 \%$ from the total powder volume.

The resulting particle size ranges were morphological and compositional characterized by Scanning Electron Microscopy using a JEOL JSM 5600LV microscope equipped with an EDX spectrometer (Oxford Instruments, INCA 200 software). Crystallographic analysis was performed by X-ray diffraction on a INEL 3000 Equinox diffractometer, operating with CoK $\alpha$ radiation $(\lambda=$ $1.79026 \AA$ ) in the angular range $2 \theta$ of $20-110^{\circ}$. Optical microscopy was performed on a VWR microscope. The milling experiments were performed with a planetary ball mill, Fritch Pulverisette 6. The main disc velocity was $350 \mathrm{rpm}$, for a hardened steel vial with 100 balls. The milling was conducted in air at several ball to powder weight ratio (BPR) for times up to $10 \mathrm{~min}$.

\section{Results and discussion}

The milling experiments on quartz sand begun with the analysis of the as received sand. As the milling has its major influence on the particle size distribution, the distribution of the particle in the as-received sand is considered firstly, and is presented in figure 1.

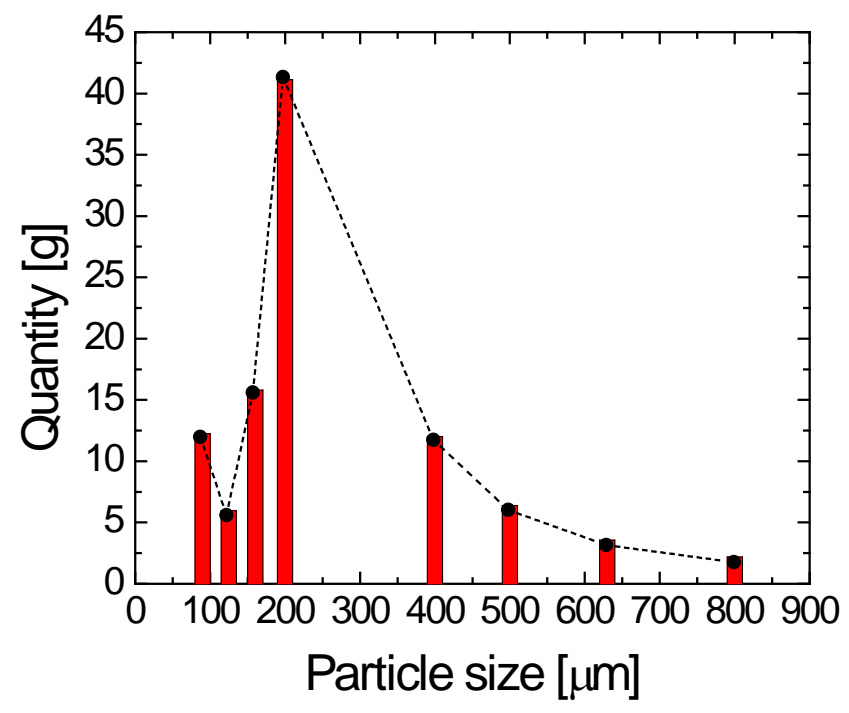

Fig. 1. Particle size distribution of the as-received sand. The distribution is obtained by sieving. 
Fig. 1 is obtained by sieving the sand with sieves having mesh between $125 \mu \mathrm{m}$ and $630 \mu \mathrm{m}$. Analyzing the particle size distribution is found that the largest quantity has sizes in the range 200 - $400 \mu \mathrm{m}$. In addition, an important quantity has sizes below $125 \mu \mathrm{m}$. The small particles are important since if they contain iron phases can be more easily removed from the sand. Even the magnetization of the iron phase is smaller, if the weight of the particle is low enough the particle can be easily extracted at lower magnetic forces.
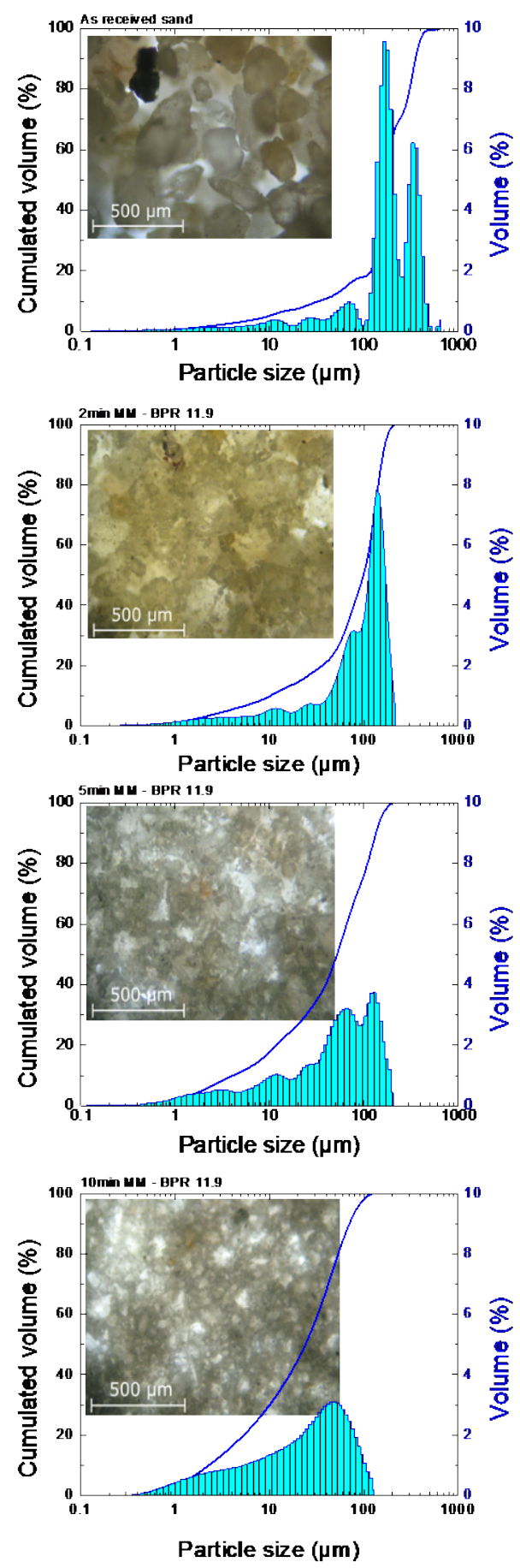
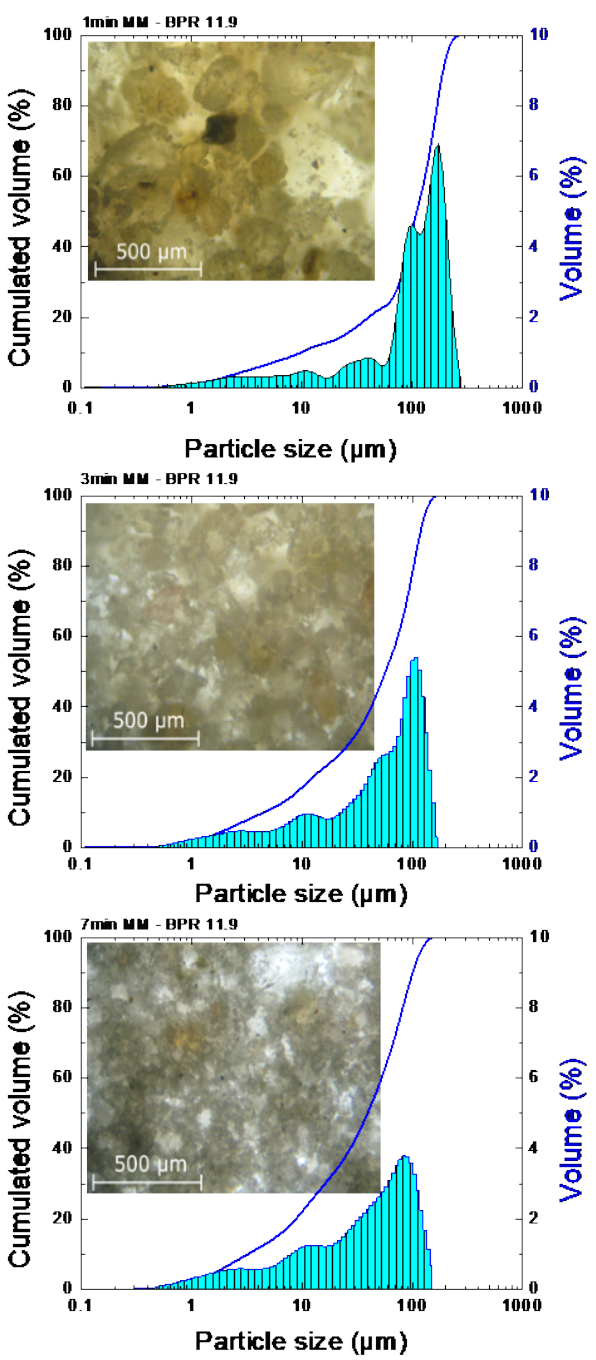

Fig. 2. Particle size distribution as a function of milling time for BPR 11.9. The insertion is the optical image of the milled sample. 
Milling of this as-received sand, leads to a shift in particle size, with influence on the sand color. In Fig. 2. The optical images and the particle size distribution is presented for several milling times. The milling conditions were the same for all samples.

As the particle modify their size, a color change occurs as the milling time increases. The color change is the effect of reflective index of light on the sand surface due to the size decrease. This color change is shown in insertions in fig.2. Milling of the sand in the 11.9 BPR, leads to a decrease of the particle size and the particle size distribution change from a $3-4$ maxima distribution to a distribution with 2 maxima. It is expected that longer milling time should lead to a single peak distribution. A longer milling time is not performed to avoid iron contamination of the sand from the balls used in the milling process. In order to proper study the particle size change by milling, in Fig. 3, the D90 parameter is plotted versus milling time.

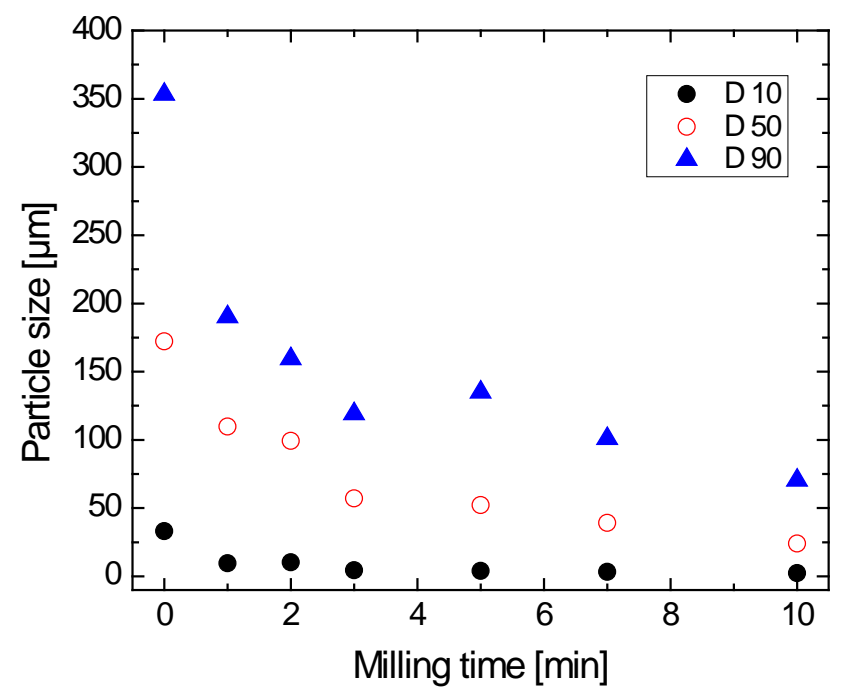

Fig. 3. D10, D50 and D90 evolution versus milling time.

It is observed that milling $10 \mathrm{~min}$, the particle size decreases 5 times comparted with the unmilled sand (as-received) (from 353 to $70 \mu \mathrm{m}$ ). The medium particle size, $50 \%$ volume powder decreases 7 times (from 172 to $24 \mu \mathrm{m}$ ). The low particle size fraction $10 \%$ volume decreases even more of 14 times (from $33 \mu \mathrm{m}$ to $2.3 \mu \mathrm{m}$ ).

To determine an optimum on the particle size, several milling conditions were considered. The main parameter changed was the ball to powder ratio (BPR). BPR controls the energy transferred to the powders, and in our case the particle shape of the sand. In fig. 4. Are presented the SEM images, recorded in backscattered mode and the particle size distributions for each chosen milling BPR.

It is seen that as the BPR value increases, the particles shapes tend to have a single distribution peak, as the particles are fragmented by collision impacts during the milling. It is assumed that for high BPR values, the energy transferred to the powders is higher. Analyzing Fig 2 and 3 it is concluded that for founding an optimum for the milling, can be considered either a change in BPR or in the milling time. Depending on the effect of iron contamination from the milling media, one of these situations can be prevail. The transferred energy is exemplified as well by the D90 parameter evolution versus BPR, Fig. 5 

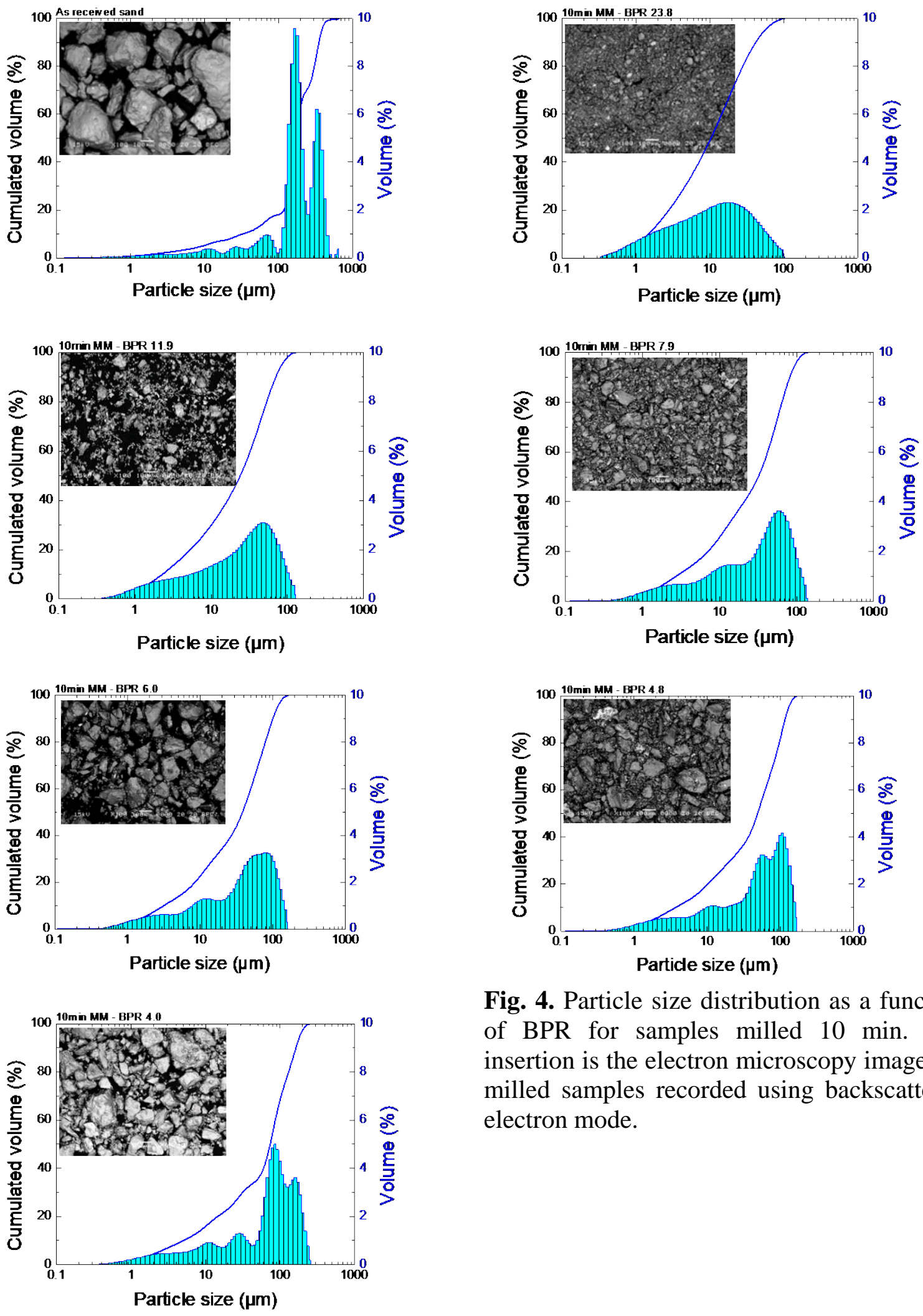

Fig. 4. Particle size distribution as a function of BPR for samples milled $10 \mathrm{~min}$. The insertion is the electron microscopy image the milled samples recorded using backscattered electron mode. 


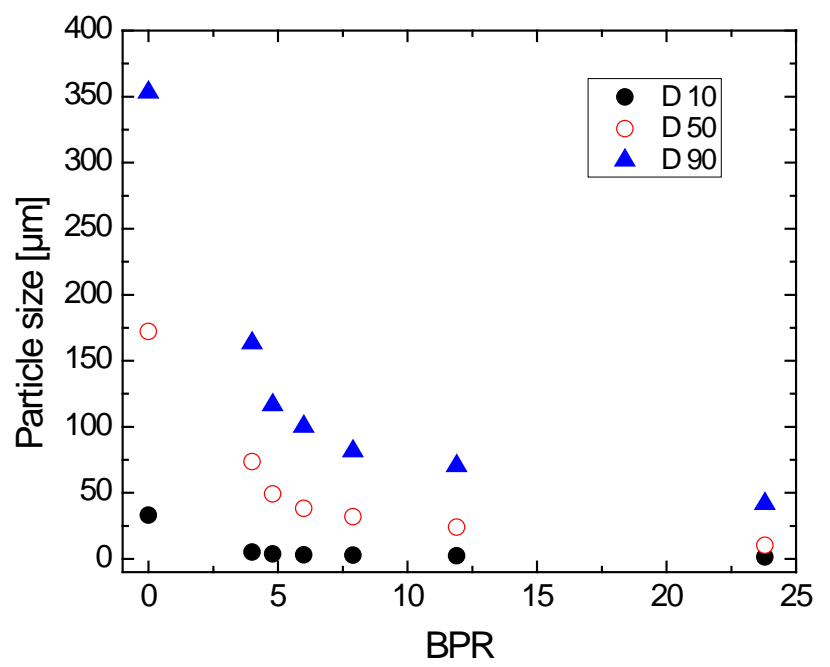

Fig. 5. D10, D50 and D90 evolution versus BPR for the samples milled 10 min.

In the case of BPR variation, the mean particle size decreases for $90 \%$ volume of powder from 350 to 163 (at 4.0 BPR) down to $41 \mu \mathrm{m}$ for 23.8 BPR. Meaning 2 times for lowest BPR (4.0) and 8 times for highest BPR (23.8). In the case of lower powder volume quantity the decrease is less pronounced. The D50 decrease from $172 \mu \mathrm{m}$ (unmilled) to $73 \mu \mathrm{m}$ (BPR 4.0) and $10 \mu \mathrm{m}$ (BPR 23.8) - meaning 2 (BPR 4.0) and 17 (BPR 23.8) times compared with unmilled sample. The smallest particles (D10) decrease from $33 \mu \mathrm{m}$ (unmilled) to $5 \mu \mathrm{m}$ (4.0 BPR) to $1.5 \mu \mathrm{m}$ (BPR 23.8). Computing the decrease ration is obtained a factor 6 for BPR 4.0 and 22 for BPR 28.9.

Since the milling of the sample is a step in the process of iron removal from the sand, distribution maps and semiquantitative analysis on the iron was performed. In Fig. 5, the iron and titanium distribution maps are presented for several BPR.

The iron and titanium distribution maps indicate that at high BPR, when the particles have small sizes, the iron is observed clearly in some small particles. On other hand at small BPR, the iron is embedded in larger particles. The occurrence of iron in small particles represents an easier way of removing him from the sand. However, computing the Fe amount from the milled samples, Fig. 6, it seems that al higher BPR the iron quantity increases, most probably due to contamination from milling balls.

Comparing to a sieved sample with particle size of $40-50 \mu \mathrm{m}$, the milling leads to a good homogenization of the iron and titanium content in the samples. This comparison suggest that Fe can be more effective removed in the samples containing small particles. If the particles are too small, and iron is not fully concentrated in individual particles the efficiency of removal process is decreased since almost all the particles will be deflected by the magnetic field. Supplementary the sieving of the sand at small particle size leads to high quantity of sand with large particle not suitable for the glass industry. 


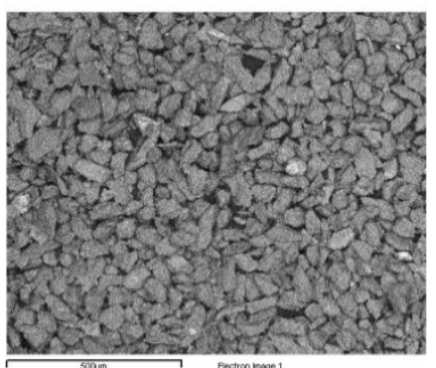

\section{Unmilled (40-50 $\mu \mathrm{m})$}

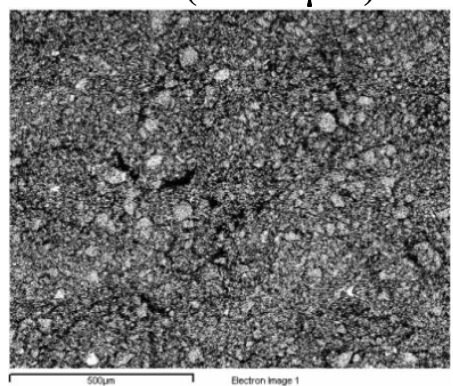

23.8

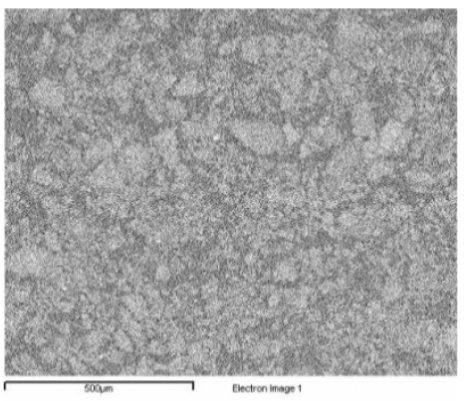

\section{9}

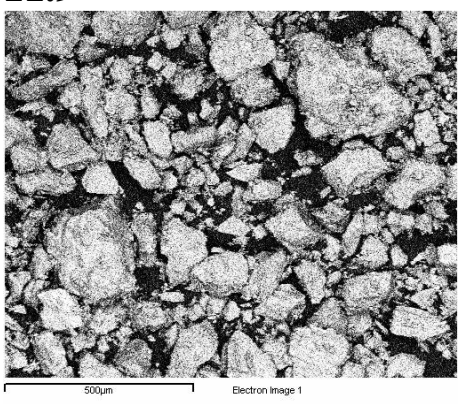

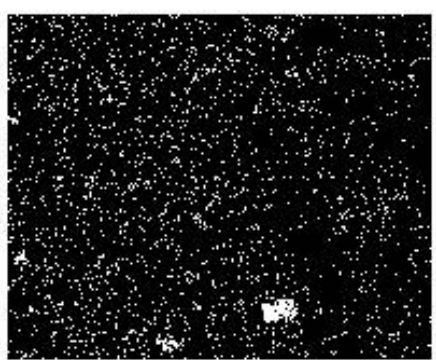

Iron Ka1

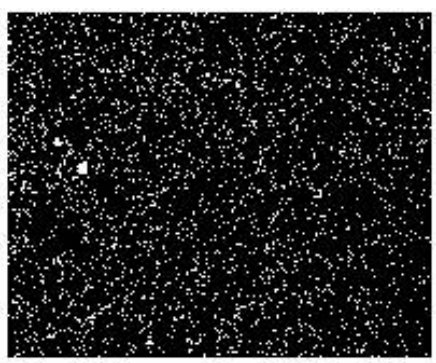

Iron Ka1

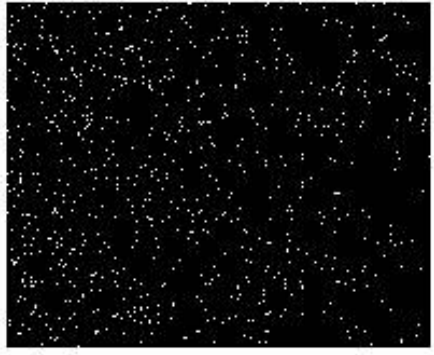

Iron Ka1

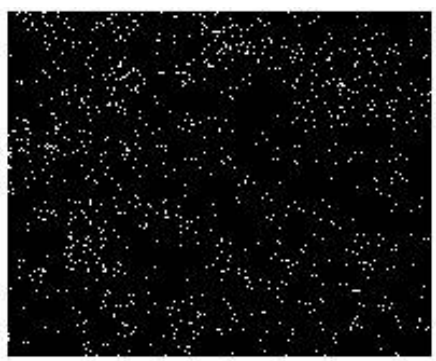

Iron Ka1

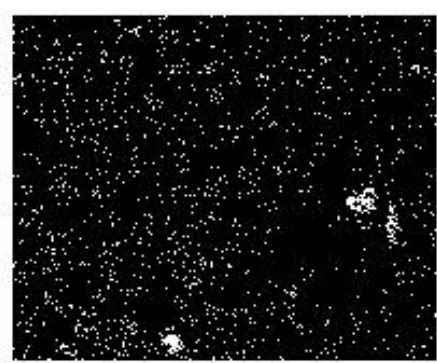

Titanium Ka1

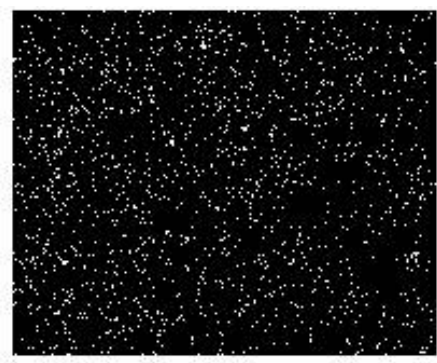

Titanium Ka1

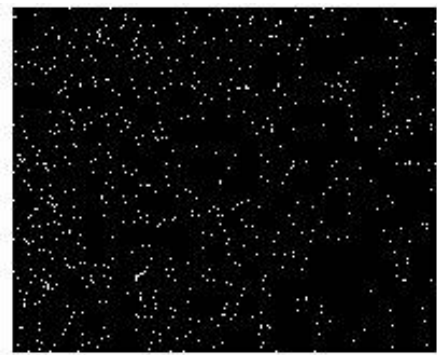

Titanium Ka1

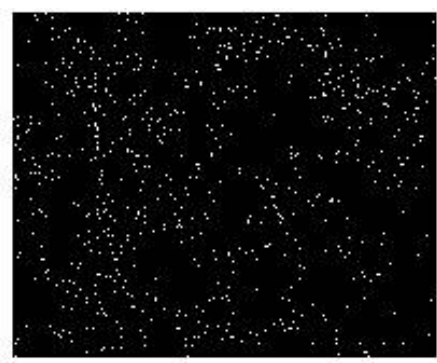

Titanium Ka1

4.0

Fig.5. Elemental distribution maps for as received sample (sieved under $50 \mu \mathrm{m}$, a) and samples milled 10 min at BPR 23.8 (b), 11.9 (c) and 4.0 (d) respectively. 

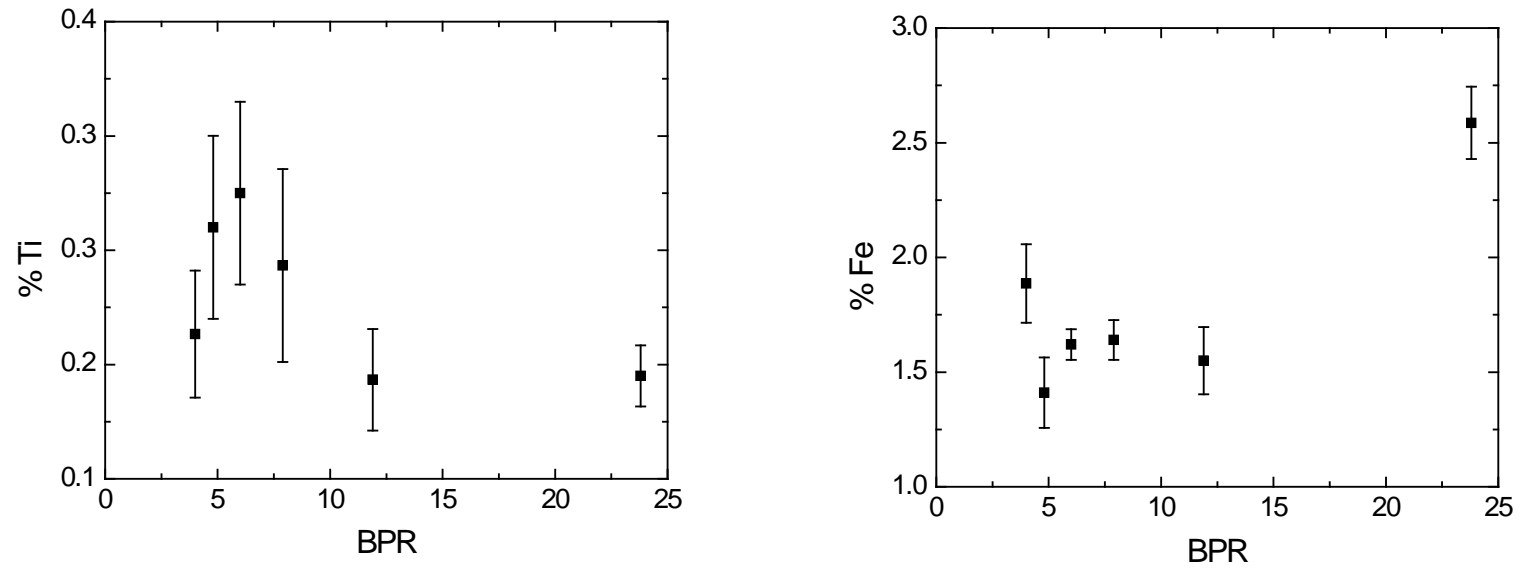

Fig. 6. Fe and Ti elemental weight evolution versus BPR.

Analyzing Fig. 6 is concluded that a BPR higher than 12 leads to iron contamination, and these milling conditions are not suitable for sand processing. Al lower BPR, the iron quantity stay at an almost constant value. Considering the titanium concentration, this element exhibits a maximum at BPR of 6, with a Gaussian distribution.

In order to check the phase modification by milling, X-ray diffraction were performed on each milling time and BPR. In Fig. 7 a are presented the X-ray pattern for the sample milled up to 10 min at a BPR of 11.9 and in Fig. 7.b are presented the X-ray patterns for the samples milled 10 min at different BPR.
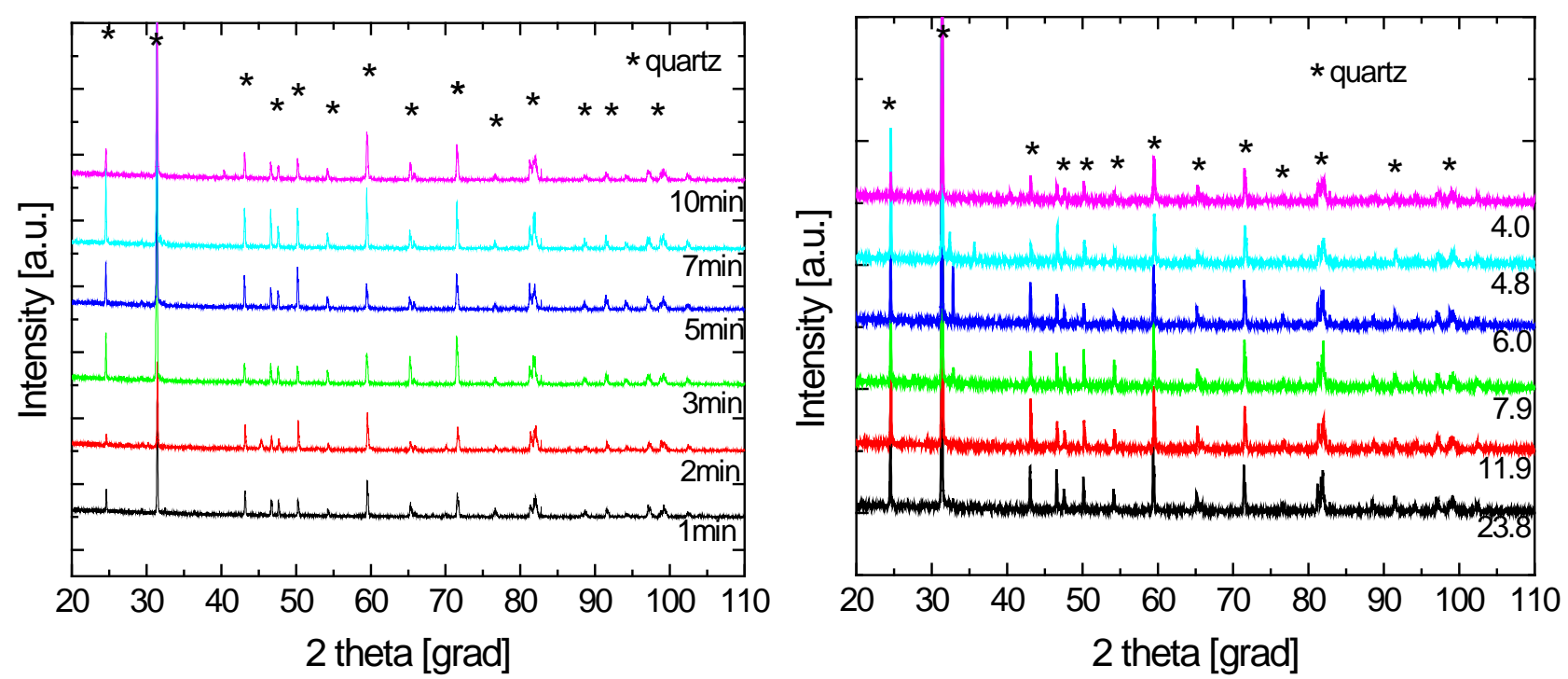

Fig. 7. X-ray diffraction patterns for samples milled up to $10 \mathrm{~min}$ (a) and for samples milled 10 min at different BPR.

From Fig. 7 it is concluded that the main phase in all the samples is quartz. All other minor phases from the as-received sand does not changes, neither the iron phases. The minor phases 
identified are $\mathrm{TiO}_{2}$ - rutile, $\mathrm{CaCo}_{3}$, anorthite $\left[\mathrm{Ca}\left(\mathrm{Al}_{2} \mathrm{Si}_{2} \mathrm{O}_{8}\right)\right]$, albite $\left[\mathrm{Na}\left(\mathrm{AlSi}_{3} \mathrm{O}_{8}\right)\right]$ and $\mathrm{FeSi}, \mathrm{Fe}_{2} \mathrm{O}_{3}$ (hematite) and $\mathrm{Fe}_{3} \mathrm{O}_{4}$ (magnetite) compounds.

Using a magnet, preliminary tests for iron removal were performed, and in Fig. 8 the removed iron quantity are plotted.

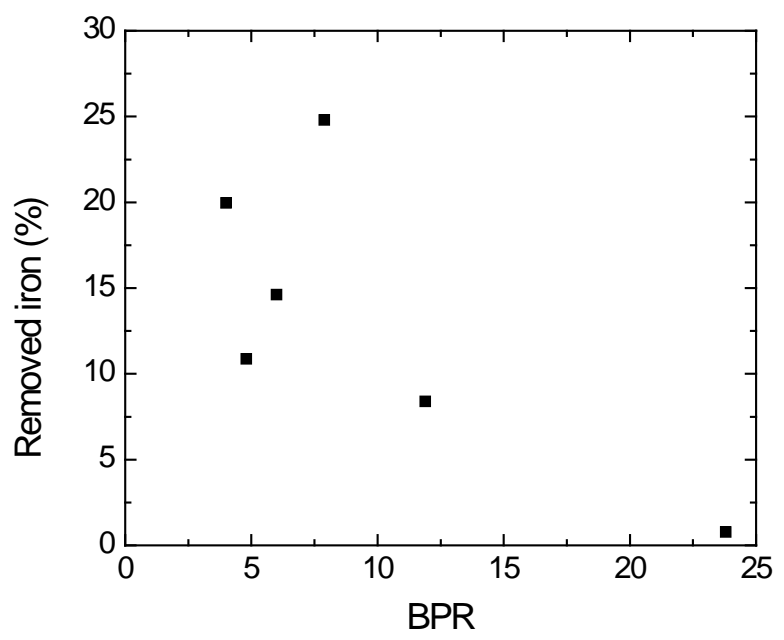

Fig. 8. Relative Fe quantity removed by magnetic separation as a BPR function.

At large BPR values, there are small differences between the iron contend before and after magnetic separation. At small BPR the differences are higher. The conclusion is that at high BPR the small particles can bond more easly with iron (from sand or from balls), making a more homogeneous sand. This observation is confirmed by particle size distribution with a single maximum. At low BPR the sand particles are fragmented, and the resulting pieces are ones with iron phases and others without iron phases, making more easily to be isolated by magnetic force.

\section{Summary}

The structural analysis of the as-received and milled samples indicates that the principal phase is quartz accompanied by small amounts of $\mathrm{SiO} 2$ phases and $\mathrm{Fe} 2 \mathrm{O} 3$. The phase structure does not modify by milling. Particle size distribution decreases exponentially with milling time and with increasing the ball to powder weight ratio. The particle size distribution is changing by milling time and BPR. At higher BPR (23.8) smallest sand quantity processed a large maximum is recorded. The Occurrence of single peak distribution is connected with the highest energy transferred to the sand. Elemental distribution maps, shows that the smaller particles in the asreceived sand can be formed almost integrally from iron phases. Processing of the sand at high BPR (low quantity sand) leads to iron homogeneous distribution due to smaller particles size resulted. Processing the sand at lower BPR (high quantity sand) non-homogenous iron phases are observed. The non-homogeneous iron distribution, but in size reduced particle sand is found to favors a better iron removal by magnetic forces. For low BPR values up to $20 \%$ of initial iron is removed by magnetic separation.

\section{Acknowledgement}

This work was supported by a grant from the Romanian National Authority for Scientific Research, CNCS -UEFISCDI, project number PN-III-P2-2.1-BG-2016-0214. 


\section{References}

[1] J. Gotze, R. Mockel, Quartz: deposits, mineralogy and analytics, Springer Verlag Berlin Heidelberg, 2012. https://doi.org/10.1007/978-3-642-22161-3

[2] S. C. Rasmussen, How Glass Changed the World: The History and Chemistry of Glass from Antiquity to the 13th Century, Springer Heidelberg New York Dordrecht London, 2012. https://doi.org/10.1007/978-3-642-28183-9

[3] M. Ma, Froth Flotation of Iron Ores. Int. J. Mining Eng. Mineral Processing. 1 (2012) 56-61. https://doi.org/10.5923/j.mining.20120102.06

[4] D.W. Frommer, Iron ore flotation: practice, problems, and prospects. J. Am Oil Chem. Soc. 44 (1967) 270-274. https://doi.org/10.1007/BF02639274

[5] Z. Zhang, J. Li, H. Huang, L. Zhou, T. Xiong, High efficiency iron removal from quartz sand using phosphoric acid. Int. J. Miner. Process. 114-117 (2012) 30-34. https://doi.org/10.1016/j.minpro.2012.09.001

[6] J. Svoboda, Magnetic Techniques for the Treatment of Materials, Ed. Kluwer Academic; 2004.

[7] N. N. Konev, Magnetic enrichment of quartz sands. Analysis of separator operation, Glass and cermics 67 (2010) 132-137. https://doi.org/10.1007/s10717-010-9246-z

[8] C. Suryanarayana- Mechanical Alloying and Milling, Ed. Marcel Dekker, New York, 2004.

[9] E. Gaffet, G. Le Caer, Mechanical processing for nanomaterials, Encyclopedia Nanoscience Nanotechnology, vol X (2004) 1-39.I

[10]H. Nazratulhuda, M. Othman, Purification of Tronoh Silica Sand via preliminary process of mechanical milling, IOP Conf. Series: Mater. Sci. Eng. 114 (2016) 012114. https://doi.org/10.1088/1757-899X/114/1/012114

[11] M. Tashakor, B. Hochwimmer, S. Imanifard, Control of grain-size distribution of serpentinite soils on mineralogy and heavy metal concentration. Asian J Earth Sci. 8 (2015) 45-53. https://doi.org/10.3923/ajes.2015.45.53

[12] M. Sundararajan, S. Ramaswamy, P. Raghavan, Evaluation for the beneficiability of white silica sands from the Overburden of Lignite mine situated in Rajpardi district of Gujarat. J Miner. Mater. Charact. Eng. 8 (2009) 701-713. https://doi.org/10.4236/jmmce.2009.89061

[13]D. A. Fungaro, M.V. da Silva, M.V, Utilization of water treatment plant sludge and coal fly ash in brick manufacturing. Am. J Environ. Protection. 5 (2014) 83-88.

[14]H.A. Khwaja, O.S. Aburizaiza, D.L. Hershey, A. Siddique, D.A.P.E. Guerrieri, J. Zeb, M. Abbass, D.R. Blake, M.M. Hussain, A.J. Aburiziza, M.A. Kramer, I.J. Simpson, Study of black sand particles from sand dunes in Badr. Saudi Arabia using electron microscopy. Atmosphere. 6 (2015) 1175-1194. https://doi.org/10.3390/atmos6081175

[15]M. P. Mubiayi, Characterisation of Sandstones: mineralogy and physical properties. Proceedings of the World Congress on Engineering 2013 Vol III, 2013.

[16] M. Lucarz, The condition of silica sand grains surface subjected to reclamation treatment. Metalurgija. 45 (2006) 37-40. 